\title{
Evaluating and modeling the impacts of mixed-mode and surface-modified column chromatography on virus filtration performance
}

\author{
Hironobu Shirataki ${ }^{1}$, Yoshiro Yokoyama ${ }^{2}$, and Ryota Oguri ${ }^{2}$ \\ ${ }^{1}$ Asahi Kasei Medical Co Ltd \\ ${ }^{2}$ Asahi Kasei Medical Co Ltd Nobeoka Area Okatomi Plant
}

September 24, 2020

\begin{abstract}
Virus filtration is a critical process in the production of biotherapeutics and drug products derived by plasma fractionation. The filterability of process solutions on virus removal filters is largely dependent on preceding downstream process steps, and column chromatography can have a particularly large impact on the throughput and flux of virus filtration. Filterability (throughput and flux) on Planova BioEX was greatly reduced for mAb and plasma IgG spiked with aggregate, and filterability improvement achieved by processing with chromatography resins (modified CEX, mixed-mode AEX and normal AEX column) was specific to protein solution. The various protein solutions spiked with aggregate showed distinct solution characteristics and by using the resulting filtration volume and flow rate, experimental and calculated filtration parameters were compared and evaluated with four clogging models: cake filtration, intermediate blocking, standard blocking and complete blocking. Effective purification of feed solutions by column chromatography has the capability to improve virus filtration processes. Further, the application of filtration parameters to the appropriate clogging model makes it possible to extrapolate filtration behavior to larger processing volumes.
\end{abstract}

\section{Introduction}

Virus filtration is widely used as a necessary virus removal step for biotherapeutics and protein drug products derived by plasma fractionation (Besnard et al., 2016; Grein et al., 2014; Miesegaes et al., 2010; Strauss et al., 2017). Virus filters have multi-layered membranes that allow for separating viruses from protein solutions, which have only a small size difference (Manabe et al., 1987, 1989). While virus removal from protein solutions is made possible by the more sensitive separation membrane, larger sized proteins and aggregates in particular have been confirmed to cause clogging in virus filters (Barnard et al., 2014; Bieberbach et al., 2019; Chen \& Chen, 2015; Genest et al., 2013). To improve the capacity of the virus filtration step, processing the feed solution through one of several commercially available prefilters has been confirmed to be effective in removing substances that cause clogging and has been widely implemented (Brown et al., 2010; Genest et al., 2013; Roederstein \& Thom, 2013). Alternatively, column chromatography has also been shown to effectively remove aggregates (Yigzaw et al., 2009).

Examination of filtration behavior and, in particular, changes in filtration behavior due to clogging can be used to elucidate the clogging mechanisms and to extrapolate filtration capacity in well characterized systems. The theoretical relationship between filtration volume and filtration throughput for a given feed solution can be fitted to one of four established clogging models for filter membranes (Grace, 1956): cake filtration, intermediate blocking filtration, standard blocking filtration and complete blocking filtration. Maximum filtration volume $\left(\mathrm{V}_{\max }\right)$ was theoretically determined using the standard blocking model based 
on filtrations conducted with a microfilter at constant pressure, and the data were then used for facility scaleup recommendations as reported in Badmington et al. (1995). Following this same strategy, the standard blocking model has been applied in nanofiltration to determine $\mathrm{V}_{\max }$ of virus filters under constant pressure (Bolton et al., 2004). Thus, small volumes of feed solution samples can be used to effectively evaluate the filtration volume or filter size that will be used in the process and additionally quantitatively compare the filterability of process solutions. Further, there have been attempts to combine several clogging models into a theoretical equation in order to match complex filtration behavior results to theoretical values (Ho \& Zydney, 2000; Bolton et al., 2006; Bolton \& Apostolidis, 2017).

In this report, monoclonal antibody $(\mathrm{mAb})$ and plasma $\operatorname{IgG}$ each spiked with aggregates prepared from the respective solution were processed by various chromatography resins or prefilter and run on a virus filter under constant pressure to determine the relationship between filtration volume (throughput) and flow rate (flux). In order to analyze the experimental results, filtration behavior results for solutions spiked with aggregates as well as several column chromatography outputs were applied to the clogging models of cake filtration, intermediate blocking, standard blocking and complete blocking, the model that best fits the filtration behavior data was identified, and clogging models were used to extrapolate filtration behavior beyond the experimental range.

\section{Materials and Methods}

\section{Monoclonal antibody}

The mAb used in this study was provided by Manufacturing Technology Association of Biologics, Japan (MAB). The mAb (pI 8.2) was grown in CHO cell culture by fed batch method, separated from cells and applied to a two-column process. The first column was a bind-elute affinity chromatography step using Protein A resin (KanCapA, Kaneka Corporation, Tokyo, Japan). The second column consisted of a cation exchange chromatography step using Cellufine MAX S-h resin (JNC Corporation) and yielded $40 \mathrm{mg} / \mathrm{mL}$ $\mathrm{mAb}$. Purified mAb was diluted with buffer containing $20 \mathrm{mM}$ Tris-Acetate, $\mathrm{pH} 7$ adjusted to $15 \mathrm{mS} / \mathrm{cm}$ with $\mathrm{NaCl}$ to produce $15 \mathrm{mg} / \mathrm{mL} \mathrm{mAb}$ solution for use in aggregate spiking experiments and $11 \mathrm{mg} / \mathrm{mL}$ for use as a reference solution for filtration. Purified $\mathrm{mAb}$ solution at $10 \mathrm{mg} / \mathrm{mL}$ was used to prepare $\mathrm{mAb}$ aggregate solution.

\section{Plasma IgG}

Venoglobulin IH5 $(50 \mathrm{mg} / \mathrm{mL})$ provided by Japan Blood Products Organization (JBPO) was diluted with $20 \mathrm{mM}$ sodium acetate, $100 \mathrm{mM} \mathrm{NaCl}$, pH 6 buffer to produce $15 \mathrm{mg} / \mathrm{mL}$ plasma IgG solution for use in aggregate spiking experiments and $11 \mathrm{mg} / \mathrm{mL}$ for use as a reference solution for filtration.

\section{Protein solution characterization}

Host cell protein (HCP) in the mAb solution was analyzed using CHO Host Cell Protein ELISA 3G Kit (Cygnus Technologies).

To determine the molecular weight distribution of proteins, size exclusion chromatography (SEC) was conducted. For analysis of mAb solutions, HPLC (Infinity 1260, Agilent) was used with a TSKgel SuperSW mAb HR column and a column guard (Tosoh). For analysis of plasma IgG solutions, HPLC (Acquity UPLC, HClass Plus System, Waters) was conducted with a TSKgel UltraSW Aggregate column and TSKgel UltraSW Aggregate Guard column (7.8 mm ID, Tosoh BioScience LLC).

$\mathrm{mAb}$ and plasma IgG recovery for chromatography and filtration steps was determined by measuring UV absorbance at $280 \mathrm{~nm}$ before and after processing steps and calculating recovery as a percentage.

\section{Aggregate spike preparations}

Aggregate solutions for aggregate spike experiments were prepared as follows. mAb aggregate solution was produced by incubating $10 \mathrm{mg} / \mathrm{mL} \mathrm{mAb}$ in $0.1 \mathrm{M} \mathrm{NaCl}, \mathrm{pH} 4$ at 60 for $60 \mathrm{~min}$, which produced a spike stock solution with aggregate content of $11.4 \%$ dimer and $33.3 \%$ trimer or larger species. 
Plasma IgG aggregate solution was prepared by mixing $5.0 \mathrm{mg} / \mathrm{mL}$ IgG in $0.1 \mathrm{M}$ glycine, adjusting to $\mathrm{pH} 2$ and incubating at room temperature for $1 \mathrm{~h}$. The produced aggregate spike solution had aggregate content of $14.8 \%$ dimer and $57.1 \%$ trimer or larger species.

\section{Column chromatography and nylon prefilter}

Protein solutions spiked with aggregate were processed and applied to liquid column chromatography conducted using an AKTA avant 25 or an AKTA pure 25 (GE Healthcare) with the following types of chromatography resins. For mAb solutions, mixed-mode AEX1 (weak AEX of primary amine in combination with weak HIC of butyl group; Cellufine MAX IB), mixed-mode AEX2 (strong AEX with quaternary amine and phenyl group in combination with strong HIC; Capto adhere, GE Healthcare) and normal AEX (Cellufine MAX Q-h) were used. For plasma IgG solutions, mixed-mode AEX1 and normal AEX were used along with modified CEX1 (cross-linked cellulose with dextran sulfate; Cellufine MAX DexS-HbP), and modified CEX2 (sulfated cellulose; Cellufine Sulfate). All Cellufine resins were supplied by JNC Corporation.

Additionally, nylon prefilter Virosart Max Minisart ( $5 \mathrm{~cm}^{2}$ surface area, Sartorius), which is considered to be effective for removing aggregates, was used as a treatment for aggregate-spiked mAb solution.

\section{Virus filter and filtration}

The virus filter used was $0.0003 \mathrm{~m}^{2}$ Planova BioEX filter (Asahi Kasei Medical Inc., Tokyo, Japan).

To prepare for filtration through the virus filter, the feed solution was filtered through a $0.2 \mu \mathrm{m}$ microfilter (Minisart RC $25 \mathrm{~mm}$, Sartorius) to remove potential precipitates and placed in a feed vessel. The feed solution was then filtered with the Planova BioEX filter under constant pressure at 0.3 or $0.35 \mathrm{MPa}$. The mass of permeate was recorded manually during the filtration run to determine flow rate, and throughput $\left(\mathrm{L} / \mathrm{m}^{2}\right)$ and flux $(\mathrm{LMH})$ were calculated.

\section{mAb with mAb aggregate spike experiments}

Purified mAb solution $(40 \mathrm{mg} / \mathrm{mL}$ ) with $175 \mathrm{ppm} \mathrm{HCP}$ and an aggregate composition of $1.4 \%$ dimer and $0.2 \%$ trimer or larger species as determined by SEC analysis was used to prepare test solutions. mAb solution $(11 \mathrm{mg} / \mathrm{mL}$ ) in $20 \mathrm{mM}$ Tris-Acetate, $\mathrm{pH} 7$ adjusted to $15 \mathrm{mS} / \mathrm{cm}$ with $\mathrm{NaCl}$ and with no aggregate spike was prepared as the "reference" solution. mAb solution prepared at $15 \mathrm{mg} / \mathrm{mL}$ in the same buffer and spiked with $1.0 \% \mathrm{mAb}$ aggregate spike was used as the control and was processed by one of these methods: column chromatography with an AEX resin (mixed-mode AEX1, mixed-mode AEX2 and normal AEX) or filtration with a nylon filter.

For column chromatography on $2 \mathrm{~mL}$ columns operated in flow-through mode, $30 \mathrm{~mL}$ of aggregate-spiked $\mathrm{mAb}$ solution was loaded at a flow rate of $0.25 \mathrm{~mL} / \mathrm{min}$ (residence time, $8 \mathrm{~min}$ ), resulting in a mAb loading capacity of $225 \mathrm{mg} / \mathrm{mL}-$ resin. Following a $10 \mathrm{~mL}$ wash with equilibration buffer (20 mM Tris-Acetate, $\mathrm{pH} 7$ adjusted to $15 \mathrm{mS} / \mathrm{cm}$ with $\mathrm{NaCl}$ ), the entire $40 \mathrm{~mL}$ output of $11 \mathrm{mg} / \mathrm{mL} \mathrm{mAb}$ was collected, and protein recovery by UV absorbance was [?]95\% for all runs.

For nylon filter treatment, aggregate-spiked mAb solution was filtered through the nylon filter, and the output was adjusted to $11 \mathrm{mg} / \mathrm{mL} \mathrm{mAb}$.

For the reference and control solutions (no processing), output from each chromatography columns and permeate from the nylon filter, $40 \mathrm{~mL}$ was prefiltered through a $0.2 \mu \mathrm{m}$ microfilter (Minisart RC $25 \mathrm{~mm}$, Sartorius) to remove potential precipitates and placed in a feed vessel. The feed solution was then filtered with a $0.0003 \mathrm{~m}^{2}$ Planova BioEX filter in constant pressure mode at $0.3 \mathrm{MPa}$. Filtration runs had a throughput of $130 \mathrm{~L} / \mathrm{m}^{2}$ or $1500 \mathrm{~g} / \mathrm{m}^{2}$, and protein recovery of [?]99\% was confirmed by UV absorbance for all runs.

\section{Plasma IgG with IgG aggregate spike experiments}

Commercially available plasma IgG (50 mg/mL) was diluted in $20 \mathrm{mM}$ sodium acetate, $100 \mathrm{mM} \mathrm{NaCl}$, pH 6 $(12 \mathrm{mS} / \mathrm{cm})$ to prepare test solutions. Plasma IgG solution at $11 \mathrm{mg} / \mathrm{mL}$ was prepared as a reference solution for virus filtration. Plasma IgG solution prepared at $15 \mathrm{mg} / \mathrm{mL}$ in the same buffer and spiked with $0.5 \% \operatorname{IgG}$ 
aggregate was used as the control and was processed by one of these types of column chromatography: AEX resin (mixed-mode AEX1 and normal AEX) or sulfate ligand resin (modified CEX1 and modified CEX2).

For column chromatography on $1 \mathrm{~mL}$ columns operated in flow-through mode, $20 \mathrm{~mL}$ of aggregate-spiked plasma IgG solution was loaded at a flow rate of $0.5 \mathrm{~mL} / \mathrm{min}$ (residence time, $2 \mathrm{~min}$ ), resulting in a plasma IgG loading capacity of $300 \mathrm{mg} / \mathrm{mL}-$ resin. Following a $7 \mathrm{~mL}$ wash with equilibration buffer $(20 \mathrm{mM}$ sodium acetate, $100 \mathrm{mM} \mathrm{NaCl}, \mathrm{pH} 6 ; 12 \mathrm{mS} / \mathrm{cm}$ ), the entire $27 \mathrm{~mL}$ output of $11 \mathrm{mg} / \mathrm{mL}$ plasma IgG was collected. Protein recovery was [?]90\% for mixed-mode AEX1 and modified CEX1 and [?]95\% for normal AEX and modified CEX2.

For the reference and control solutions (no processing) and the output from each chromatography column at $11 \mathrm{mg} / \mathrm{mL}, 27 \mathrm{~mL}$ was filtered with a $0.0003 \mathrm{~m}^{2}$ Planova BioEX filter in constant pressure mode at $0.35 \mathrm{MPa}$. Filtration runs had a throughput of $90 \mathrm{~L} / \mathrm{m}^{2}$ or $900 \mathrm{~g} / \mathrm{m}^{2}$, and protein recovery of [?] $99 \%$ was confirmed by UV absorbance for all runs.

\section{Clogging model analysis}

Filtration behavior was evaluated with the following four clogging models: cake filtration, intermediate blocking, standard blocking and complete blocking. Considering that filtration occurs as the filtration solution passes through a collection of uniform cylindrical pores of some length and inner diameter, these models can be used to express the theoretical filter behavior due to changes in flow path resistance as a result of substances that cause clogging being retained in the filter based on shape. Equations expressing the relationship between filtration volume (throughput) and flow rate (flux) for the four clogging models applied to constant pressure filtration as described in Sumiya (2013) and Grace (1956) are shown below.

\section{Cake filtration model}

In this clogging model, the substances causing clogging do not block the inside of the cylindrical pores but rather adhere to the pore surface, causing the formation of flow paths that are new and different from those of the filter material.

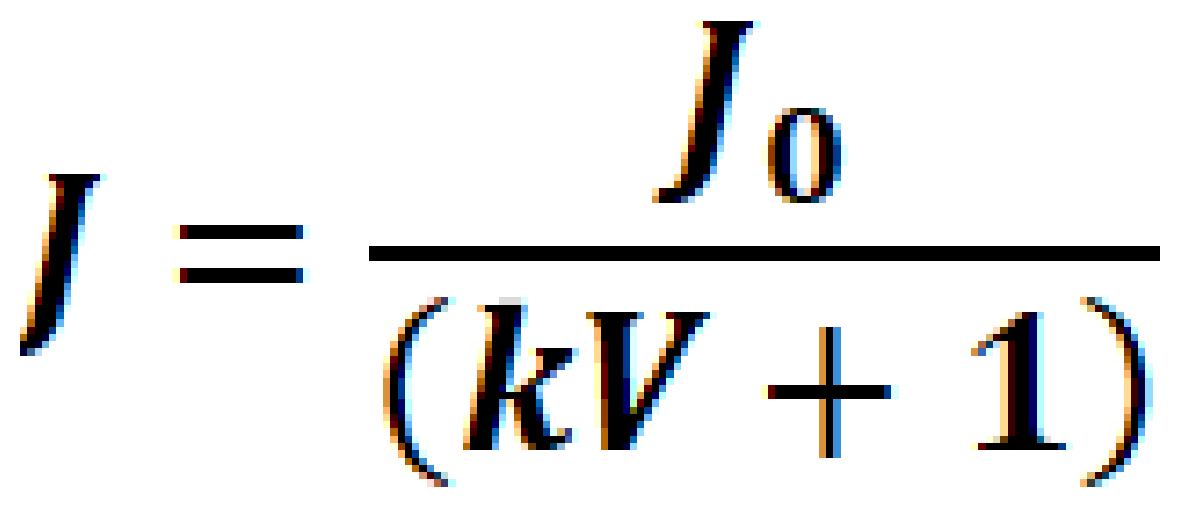

(1) 


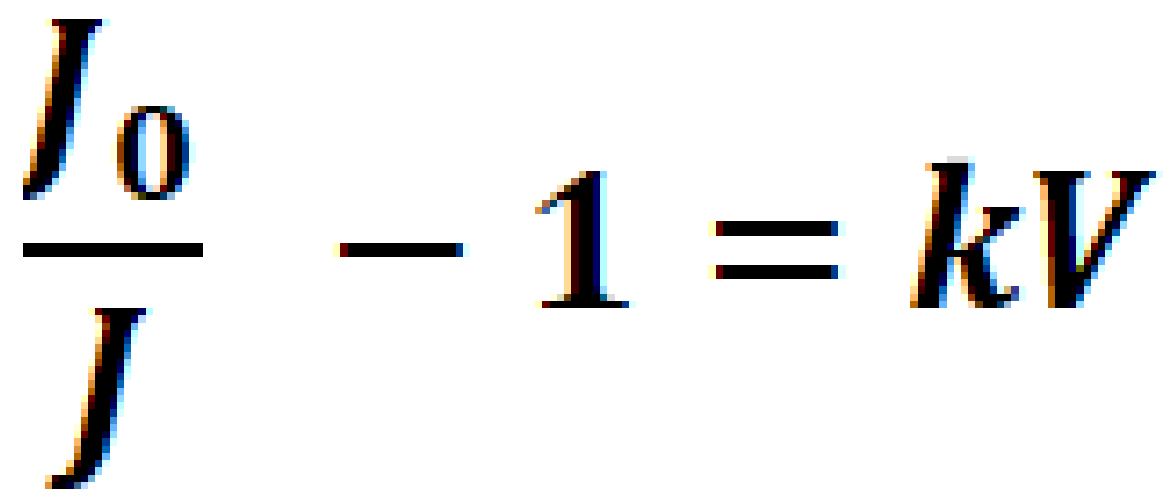

(2)

where $\mathrm{J}_{0}$ is the initial flow rate, $\mathrm{J}$ is the flow rate achieved by the filtration solution at filtration volume, $\mathrm{V}$, and $\mathrm{k}$ is the clogging factor specific to the solution being filtered.

\section{Intermediate blocking model}

In this clogging model, the substances causing clogging accumulate on already trapped substances and the entrances of the cylindrical pores.

$$
J=J_{0} \exp (-k V)
$$

(3)

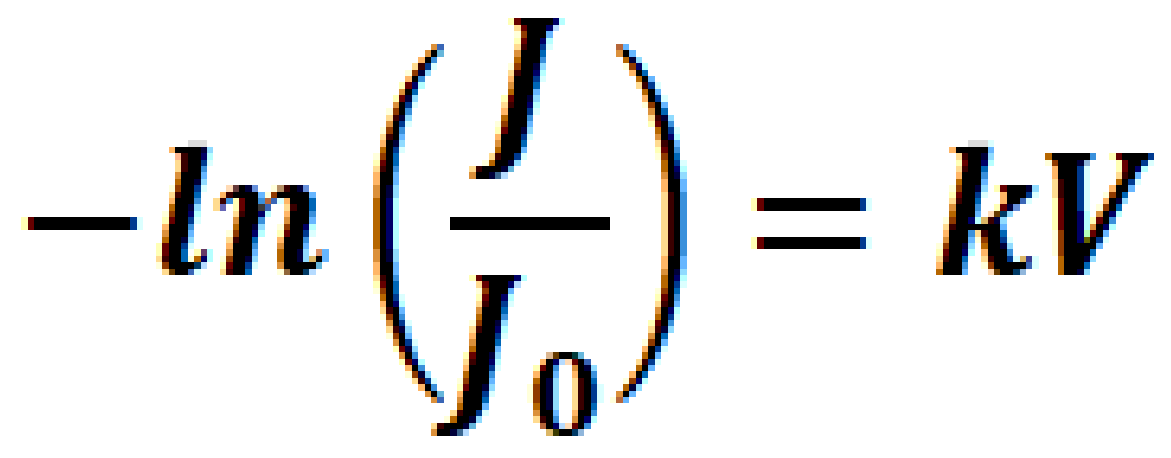

(4)

\section{Standard blocking model}

In this clogging model, the substances causing clogging are distributed evenly over the inner walls of the cylindrical pores, and the inner diameter of the pores gradually becomes smaller. 


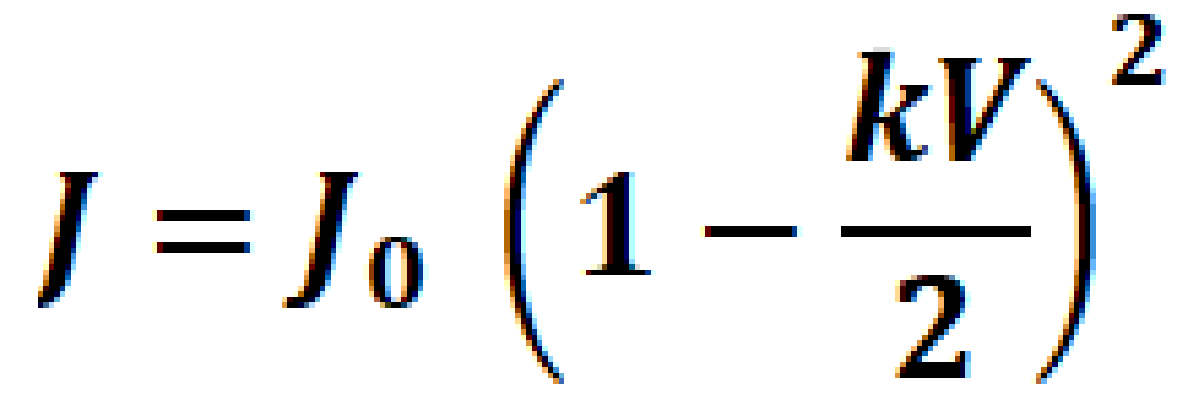

$(5)$

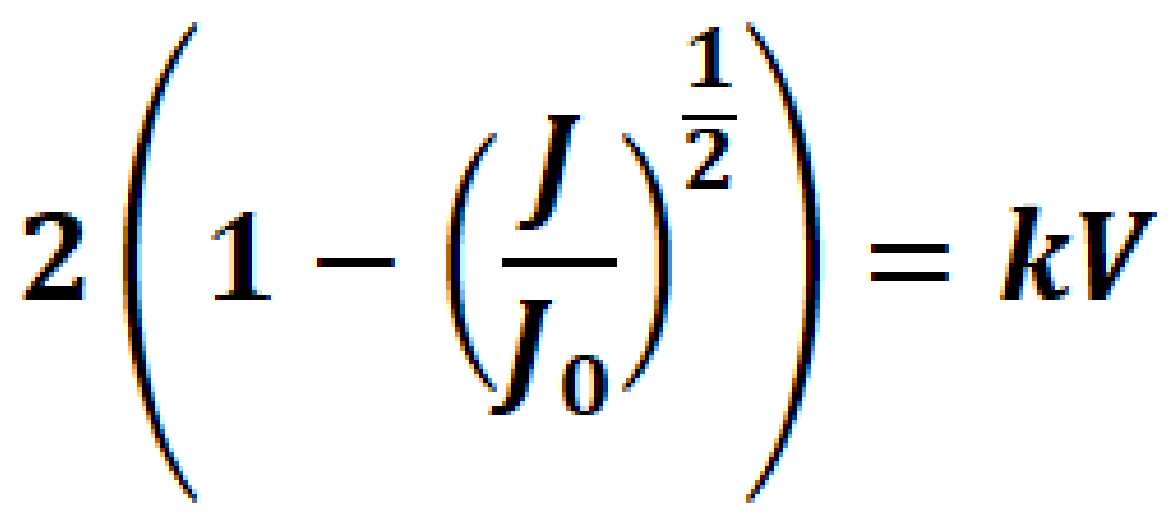

(6)

Complete blocking model

In this clogging model, the substances causing clogging accumulate at the entrance of the cylindrical pores, and accumulation continues until all of the pores become clogged.

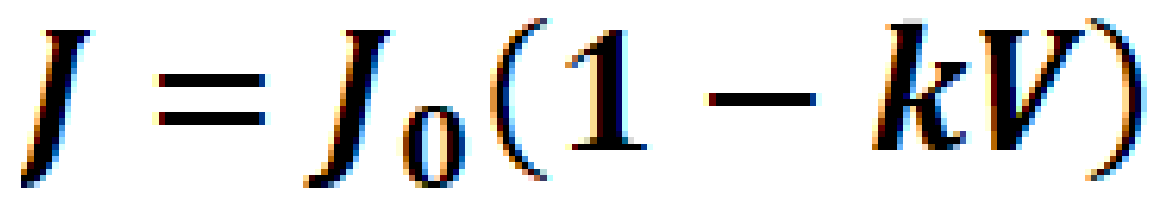

(7) 


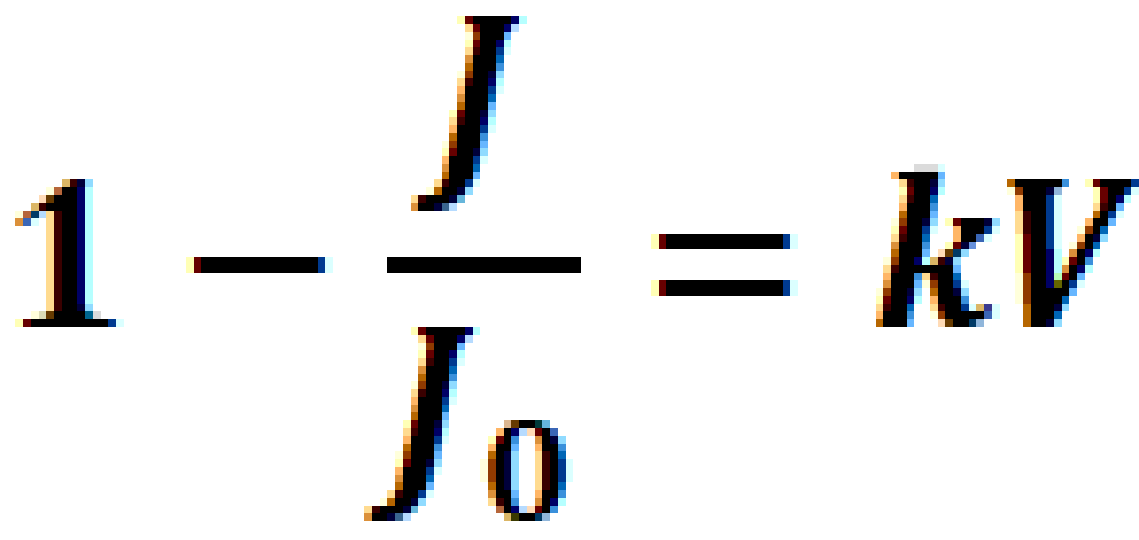

(8)

Filtration behavior parameters (filtration volume and flow rate) were applied to the rearranged equations for each clogging model (Equations 2, 4,6 and 8 ), and the left side of each equation was plotted against filtration volume, $\mathrm{V}$, expressed as throughput $\left(\mathrm{L} / \mathrm{m}^{2}\right)$, and $\mathrm{k}$ was obtained for each model as the slope. According to Grace (1956), $\mathrm{k}$ is proportional to the volume of solid particles removed by filtration.

Differences between experimental values and modeling results were plotted and compared for all four models. Using $\mathrm{k}$, theoretical filtration volume and flow rate were obtained using Equations 1, 3, 5 and 7, and the mean difference between the experimental and calculated values at each point of measurement was obtained by Equation 9 for each solution and model.

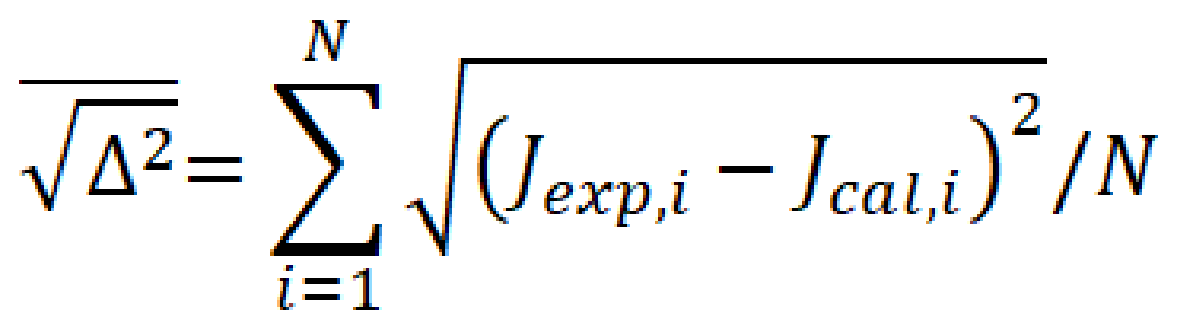

(9)

Here, $J_{\text {exp }, i}$ and $J_{c a l, i}$ are the $\mathrm{i}^{\text {th }}$ filtration behavior measurement for experimental and calculated flow rate values and $N$ is the number of experimental measurements for each solution. The smaller the mean difference between experimental and calculated values obtained using Equation 9, the better the fit of the clogging model.

\section{Results}

\section{Column chromatography and filtration for $\mathrm{mAb}$ with aggregate spike}

From the filtration results shown in Figure 1 and protein characterization data shown in Table 1, we see that the purified $\mathrm{mAb}$ (reference solution) with $175 \mathrm{ppm} \mathrm{HCP}$ and $1.3 \%$ dimer content showed a stable flow rate on Planova BioEX. The control, which is aggregate-spiked $\mathrm{mAb}$ (spiked at 1.0\%), has markedly lower throughput from shortly after the start of filtration, showing that an increase in larger aggregate (trimer or larger species) content from $0.2 \%$ to $1.2 \%$ is the likely cause for the marked decrease in filterability. Further, aggregate-spiked mAb processed in flow-through mode with normal AEX has similarly high larger aggregate content and filtration behavior that is almost the same as the control, showing that normal AEX column 
chromatography has no impact on improving filterability. The moderate improvement by the nylon prefilter on filterability of the aggregate-spiked $\mathrm{mAb}$ can be attributed to the reduction of larger aggregates to $0.5 \%$, which is less than half of the level in the control. The output from mixed-mode AEX1 and mixed-mode AEX2 showed markedly higher filterability, surprisingly higher than the reference. These chromatography processes effectively reduced HCP and aggregate, particularly reducing larger aggregates to below detectable levels. HCP was also decreased for both outputs, but the similar improvement in filterability increase observed for both despite mixed-mode AEX2 output having twice the HCP as mixed-mode AEX1 output suggests that the cause of decreased filterability for aggregate-spiked mAb is larger aggregates more so than HCP. These results suggest that filterability was not greatly impacted by the $\mathrm{HCP}$ or $\mathrm{mAb}$ dimer content at these concentrations.

The molecular weight distribution profiles based on SEC analysis shown in Figure 2 for the reference, control, mixed-mode AEX1 output and nylon prefilter output shows the changes in aggregate content and changes in the distribution for these various solutions. The aggregate-spiked mAb (control) has increased dimer and larger aggregate content, which is believed to have a great impact on filterability in the virus filtration step. Further, filterability at the virus filtration step is markedly increased by mixed-mode AEX1 processing, and the molecular weight distribution profile clearly shows that this processing almost completely removed larger aggregates and reduced the dimer content. Filtering the solution with a nylon prefilter moderately improved filterability and it decreased the proportion of larger aggregates, but its effect on improving filterability is very small compared to mixed-mode AEX1.

\section{Column chromatography and filtration for plasma IgG with aggregate spike}

Figure 3 shows the effect of column chromatography on the filterability of polyclonal plasma IgG isolated from plasma derivatives with $0.5 \%$ aggregate spike. Plasma IgG spiked with $0.5 \%$ IgG aggregate (control) had increased larger aggregate content (from $0.3 \%$ for the reference solution to $0.5 \%$ ) and $7.8 \%$ dimer content (Table 2). The figure clearly shows that the $0.5 \%$ IgG aggregate spike causes a marked decrease in filterability as evidenced by achieving flux of $100 \mathrm{LMH}$ at nearly $80 \mathrm{~L} / \mathrm{m}^{2}$ for the reference, while the flux of the control had become nearly zero and the run was ended by $12 \mathrm{~L} / \mathrm{m}^{2}$. Normal AEX processing of aggregate-spiked plasma IgG produced no aggregate removal was observed and there was no improvement in filterability.

Mixed-mode AEX1 showed more than double the throughput of the control and high aggregate removal with dimer content decreasing from $7.8 \%$ to $5.8 \%$ and larger aggregate content decreasing from $0.5 \%$ to $0 \%$. On the other hand, while larger aggregate content was also reduced to $0 \%$ by modified CEX1 and modified CEX2 processing, dimer was not reduced markedly from the control and remained at $7.3 \%$ and $7.7 \%$, respectively. Interestingly, modified CEX output showed significantly higher filterability than the mixed-mode AEX1 output and even exceeded the flux of the reference in the early phase of filtration (Figure 3b). Modified CEX1 and modified CEX2 both show high filterability, but modified CEX2 output shows a greater flux decay than does modified CEX1 output.

\section{Clogging model analysis for aggregate-spiked mAb}

Evaluation of the filtration behavior for the reference, control, mixed-mode AEX1 output and normal AEX output for aggregate-spiked mAb solutions in Figure 1 with each of the four clogging models is shown in Figure 4. The reference solution (no aggregate spike) and the output from mixed-mode AEX1 (complete removal of larger aggregate species) showed good agreement between experimental and calculated values, with plots for all four models being almost entirely identical and overlapping with the plot of experimental results (Figure 4a and 4c). In contrast, the control (aggregate-spiked mAb) and output from normal AEX (minimal aggregate removal) had different plots for each clogging model, and in both of these cases, the standard blocking model plot overlapped the most with experimental values (Figure $4 \mathrm{~b}$ and $4 \mathrm{~d}$ ).

The calculated $\mathrm{k}$ for output from mixed-mode AEX1 and mixed-mode AEX2 was smallest, at around 0.001, followed by reference (no aggregate spike) at around 0.002 (Figure 5a). For these solutions with low proportions of aggregate, $\mathrm{k}$ was almost the same for all four clogging models, and all of the clogging models show good agreement with experimental values. On the other hand, the control, output from normal AEX and 
output from nylon prefilter (all three solutions having relatively high proportions of larger aggregate content) had markedly higher $\mathrm{k}$ than column output from mixed-mode AEX (low proportion of aggregate), and the higher the aggregate content, the larger the k. Further, for all three solutions with larger aggregates, the $\mathrm{k}$ decreased in the order of cake filtration, intermediate blocking, standard blocking and complete blocking models.

The differences between experimental and calculated values for each solution with all four clogging models in Figure 5b show that for solutions with high aggregate content and high $\mathrm{k}$ filtered on a virus filter at constant pressure, the standard blocking model is the best fit. On the other hand, for solutions with low aggregate proportion and small $\mathrm{k}$, there was practically no difference between experimental and calculated values for all four clogging models, and it is suggested that the clogging model results are indistinguishable from each other for solutions with stable filtration behavior without clear clogging for the throughput tested.

\section{Clogging model analysis for aggregate-spiked plasma IgG}

Evaluation of the filtration behavior for the reference, control, modified CEX1 output and normal AEX output for aggregate-spiked plasma IgG solutions in Figure 3 with each of the four clogging models is shown in Figure 6. The reference solution (no aggregate spike) and modified CEX output (complete removal of larger aggregate species) showed good agreement between experimental and calculated results for all four clogging models, with all four calculated plot lines being almost identical and overlapping with the experimental results (Figure 6a and 6c). In contrast, control (spiked with aggregate) and normal AEX output (no aggregate removal) had different plots for each clogging model, and in both of these cases, the complete blocking model showed the smallest differences between experimental and calculated values (Figure $6 \mathrm{~b}$ and $6 \mathrm{~d})$.

Figure 7 shows the plots of $\mathrm{k}$ and mean differences between experimental and calculated values for filtration behavior shown in Figure 3 for plasma IgG. From Figure 7a, the reference (no aggregate spike) and output from modified CEX1 and modified CEX2 (complete removal of larger aggregate species) was 0.01 or smaller for all of the clogging models, and modified CEX1 had the smallest $\mathrm{k}$ for all models. For output from modified CEX2 and reference, $\mathrm{k}$ was smallest for the complete blocking model, but along with output from modified CEX1, these three solutions had almost the same $\mathrm{k}$ irrespective of clogging model. On the other hand, the control and output from normal AEX (both with relatively high proportions of larger aggregate content) had markedly higher $\mathrm{k}$ than column outputs with relatively low proportion of aggregate.

The differences between experimental and calculated values for each solution and all four clogging models in Figure $7 \mathrm{~b}$ show that for solutions with relatively high proportions of larger aggregate content (output from normal AEX) and no aggregate content (output from mixed-mode AEX1), both show the best fit with the complete blocking model. The differences between experimental and calculated values were very small for the three solutions with small $\mathrm{k}$, namely the reference, output from modified CEX1 and output from modified CEX2, and the cake filtration model shows a slightly smaller difference between experimental values and calculated values than the other clogging models for reference and output from modified CEX2. A deeply interesting point is that the output for mixed-mode AEX1, which removed the larger aggregates through column chromatography and had lower dimer content than the outputs for modified CEX1 and modified CEX2 (5.8\% vs. $7.3 \%$ and $7.7 \%$, respectively), had a markedly higher $\mathrm{k}$ than the output for both modified CEX resins and the reference, which had $0.3 \%$ larger aggregate content. These results along with the SEC data for mAb solutions in Figure 2 suggest that there are components besides aggregates detected by SEC that impede the filterability of plasma IgG on a virus filter, and these components formed in the process of producing aggregates are reduced by processing by modified CEX but not by modified AEX1.

\section{Extrapolating process capacity using clogging models}

From Figure 7b, reference plasma IgG (no aggregate spike) showed good agreement between the experimental and calculated values for all four clogging models, but this is based on experimental results from filtration throughput up to $100 \mathrm{~L} / \mathrm{m}^{2}$. It is of great interest and thought to be of importance to know whether this experimental data could be used to predict filtration behavior for throughput beyond this range. In order to 
calculate and compare the maximum practical throughput for the filtration of plasma IgG solution without aggregate spiking shown in Figure 6a, the theoretical filtration behavior plots calculated using each clogging factor and clogging model for much larger filtration volumes is shown in Figure 8. From this extrapolation, for larger filtration volumes, the different clogging models have varying maximum filtration volumes: about $250 \mathrm{~L} / \mathrm{m}^{2}$ for complete blocking model, about $350 \mathrm{~L} / \mathrm{m}^{2}$ for standard blocking model, about $1000 \mathrm{~L} / \mathrm{m}^{2}$ for intermediate blocking model and $2000 \mathrm{~L} / \mathrm{m}^{2}$ or more for the cake filtration model.

\section{Discussion}

Based on analysis of filtration behavior and the impacts of the addition of column chromatography on filterability, users can consider choosing chromatography resins to improve the overall performance of their virus filtration process. For aggregate-spiked mAb processing, the output from mixed-mode AEX1 and mixedmode AEX2 showed improved filterability while normal AEX did not. Based on manufacturer information on the resins, mixed-mode AEX1 has primary amine and butyl base, and mixed-mode AEX2 has tertiary amine and phenyl group, and as such, these mixed-mode AEX media do not rely on the strength and weakness of an anion exchange group and hydrophobic group. Similarly, for aggregate-spiked plasma IgG processing, filterability was improved over reference by two resins with a sulfate ligand, modified CEX1 with dextran sulfate and modified CEX2 with cellulose sulfate, indicating that plasma IgG filterability improvement is due to the more effective dextran sulfate flow-through processing. However, while both mixed-mode AEX and modified CEX column chromatography removed larger aggregates from plasma IgG, there were differences in removal of dimers by these two methods. Despite greater removal by mixed-mode AEX, modified CEX showed markedly better improvement in filterability with flux at the start of the filtration exceeding that for the reference. This observation suggests that the decrease in filterability of plasma IgG, which is polyclonal, is not dependent solely on the aggregate content determined by SEC, unlike the pattern observed for $\mathrm{mAb}$ solutions.

From clogging model results, we see that the clogging model that best matches the filtration behavior for each protein filtration under constant pressure filtration with Planova BioEX filters clearly differed with the properties of the solution being filtered. Solutions showing extreme clogging, such as plasma $\operatorname{IgG}$ aggregate spike, follow the complete blocking model, and solutions showing minor clogging, such as aggregatespiked mAb, follow the standard clogging model. The results from all four clogging models are practically indistinguishable for solutions that do not include any spiked substances that cause clogging, with the cake filtration model having a slightly better fit than other clogging models.

Although the clogging models assume simplified uniform cylindrical pores, which may not be exactly representative of virus filters, based on the studies and analyses presented here, applying the appropriate clogging models to filtration behavior is an insightful way to characterize filtration processes.

By selecting chromatography processes that are compatible with virus filtration and that improve the filterability of the feed stream, users can increase the capacity of their production processes. For mAb, for example, these processes can be conducted at large scales of at least $1000 \mathrm{~L} / \mathrm{m}^{2}$, and even larger throughput can be expected as has already been put into practice (Lute et al., 2020). By evaluating process filterability, determining the best fit clogging model and utilizing it, total virus filtration process throughput can be estimated and used for planning purposes.

As future work, application of visualization techniques will add valuable information and contribute to better understanding of clogging mechanisms.

\section{Acknowledgements}

The authors would like to thank Yoshihiro Matsumoto and Shigeyuki Aoyama of JNC Corporation for column chromatography purification and SEC analysis of the mAb solution. The authors thank Linda Gudex and Akira Wada (Asahi Kasei Bioprocess America) for their assistance with manuscript preparation. The authors also thank Dr. Daniel Strauss and Dr. Julie Kozaili (Asahi Kasei Bioprocess America) for their critical reviews of the manuscript prior to submission. This research was supported by Japan Agency for 
Medical Research and Development (AMED) under grant number JP19ae0101057.

\section{References}

Badmington, F., Wilkins, R., Payne, M., \& Honig, E. S. (1995). Vmax testing for practical microfiltration train scale-up in biopharmaceutical processing. Pharmaceutical Technology ,19 (9), 64-76.

Barnard, J. G., Kahn, D., Cetlin, D., Randolph, T. W., \& Carpenter, J. F. (2014). Investigations into the fouling mechanism of parvovirus filters during filtration of freeze-thawed $\mathrm{mAb}$ drug substance solutions.Journal of Pharmaceutical Sciences , 103 (3), 890-899. https://doi.org/10.1002/jps.23881

Besnard, L., Fabre, V., Fettig, M., Gousseinov, E., Kawakami, Y., Laroudie, N., Scanlan, C., \& Pattnaik, P. (2016). Clarification of vaccines: An overview of filter based technology trends and best practices. Biotechnology Advances , 34 (1), 1-13. https://doi.org/10.1016/j.biotechadv.2015.11.005

Bieberbach, M., Kosiol, P., Seay, A., Bennecke, M., Hansmann, B., Hepbildikler, S., \& Thom, V. (2019). Investigation of fouling mechanisms of virus filters during the filtration of protein solutions using a high throughput filtration screening device. Biotechnology Progress , 35 (4), e2776. https://doi.org/10.1002/btpr.2776

Bolton, G. R., \& Apostolidis, A. J. (2017). Mechanistic modeling of the loss of protein sieving due to internal and external fouling of microfilters. Biotechnology Progress, 33 (5), 1323-1333.

Bolton, G., LaCasse, D., \& Kuriyel, R. (2006). Combined models of membrane fouling: development and application to microfiltration and ultrafiltration of biological fluids. Journal of Membrane Science, 277 (1-2), 75-84. https://doi.org/10.1002/btpr.2514

Bolton, G., Siwak, M., Ireland, T. \& Lutz, H. (2004). Viral filtration of plasma-derived human IgG. Biopharm International ,17 (11), 38-44.

Brown, A., Bechtel, C., Bill, J., Liu, H., Liu, J., McDonald, D., Pai, S., Radhamohan, A., Renslow, R., Thayer, B., Yohe, S., \& Dowd, C. (2010). Increasing parvovirus filter throughput of monoclonal antibodies using ion exchange membrane adsorptive pre-filtration.Biotechnology and Bioengineering, 106 (4), 627-637. https://doi.org/10.1002/bit.22729

Chen, Q., \& Chen, D. (2015). Viral clearance of traditional unit operations: Virusretentive filtration. PDA Journal of Pharmaceutical Science and Technology , 69 (1), 142-153. https://doi.org/10.5731/pdajpst.2015.01038

Genest, P., Ruppach, H., Geyer, C., Asper, M., Parrella, J., Evans, B., \& Slocum, A. (2013). Artifacts of virus filter validation. BioProcess International , 11 (5), 54-61.

Grace, H. P. (1956). Structure and performance of filter media. II. Performance of filter media in liquid service. AIChE Journal , 2 (3), 316-336. https://doi.org/10.1002/aic.690020308

Grein, T. A., Michalsky, R., \& Czermak, P. (2014). Virus separation using membranes. In R. Pörtner (Ed.), Animal Cell Biotechnology(Vol. 1104, pp. 459-491). Methods in Molecular Biology (Methods and Protocols). https://doi.org/10.1007/978-1-62703-733-4_26

Ho, C. C., \& Zydney, A. L. (2000). A combined pore blockage and cake filtration model for protein fouling during microfiltration. Journal of Colloid and Interface Science , 232 (2), 389-399. https://doi.org/10.1006/jcis.2000.7231

Lute, S., Kozaili, J., Johnson, S., Kobayashi, K., \& Strauss, D. (2020). Development of small scale models to understand the impact of continuous downstream bioprocessing on integrated virus filtration. Biotechnology Progress , 36 (3), e2962. https://doi.org/10.1002/btpr.2962

Manabe, S., Kamata, Y., Iijima, H., \& Kamide, K. (1987). Some morphological characteristics of porous polymeric membranes prepared by "micro-phase separation method". Polymer Journal , 19 (4), 391-404. https://doi.org/10.1295/polymj.19.391 
Manabe, S., Tsurumi, T., Ishikawa, G., Satani, M., Yamashiki, T., Hamamoto, Y., Yamaguchi, K., Kobayashi, S., \& Yamamoto, N. (1989). Mechanism of immunodeficiency virus (HIV) removal by regenerated cellulose hollow fiber (BMM). Membrane, 14 (1), 77-83. https://doi.org/10.5360/membrane.14.77

Miesegaes, G., Lute, S., \& Brorson, K. (2010). Analysis of viral clearance unit operations for monoclonal antibodies. Biotechnology and Bioengineering , 106 (2), 238-246. https://doi.org/10.1002/bit.22662

Roederstein, S., \& Thom, V. (2013). Virus filtration using a high-throughput parvovirus-retentive membrane. BioPharm International , 2013(1) (Suppl.)

Strauss, D., Goldstein, J., Hongo-Hirasaki, T., Yokoyama, Y., Hirotomi, N., Miyabayashi, T., \& Vacante, D. (2017). Characterizing the impact of pressure on virus filtration processes and establishing design spaces to ensure effective parvovirus removal. Biotechnology Progress ,33 (5), 1294-1302. https://doi.org/10.1002/btpr.2506

Sumiya, M. (2013). Heisokuriron no kaisetsu to roka kekka he no tekiyo [Explanation of clogging theories and their application to filtration results], SPRING Pall News , 117, 10-15.

Yigzaw, Y., Hinckley, P., Hewig, A., \& Vedantham, G. (2009). Ion exchange chromatography of proteins and clearance of aggregates.Current Pharmaceutical Biotechnology, 10 (4), 421-426.

\section{Tables}

Table $1 \mathrm{HCP}$, dimer and trimer or larger species content of aggregate-spiked mAb solutions used in the virus filtration process.

\begin{tabular}{|c|c|c|c|c|c|c|}
\hline & Reference $^{+}$ & Control $^{++}$ & $\begin{array}{l}\text { Output of } \\
\text { column } \\
\text { and nylon } \\
\text { prefilter } \\
\text { treatment } \\
\text { Mixed-mode } \\
\text { AEX1 }\end{array}$ & $\begin{array}{l}\text { Output of } \\
\text { column } \\
\text { and nylon } \\
\text { prefilter } \\
\text { treatment } \\
\text { Mixed-mode } \\
\text { AEX2 }\end{array}$ & $\begin{array}{l}\text { Output of } \\
\text { column } \\
\text { and nylon } \\
\text { prefilter } \\
\text { treatment } \\
\text { Normal } \\
\text { AEX }\end{array}$ & $\begin{array}{l}\text { Output of } \\
\text { column } \\
\text { and nylon } \\
\text { prefilter } \\
\text { treatment } \\
\text { Nylon } \\
\text { prefilter }\end{array}$ \\
\hline $\begin{array}{l}\mathrm{HCP} \\
(\mathrm{ppm})\end{array}$ & 175 & 173 & 26 & 59 & 137 & 116 \\
\hline Dimer (\%) & 1.3 & 1.8 & 1.0 & 1.0 & 1.9 & 1.5 \\
\hline $\begin{array}{l}{[?] \text { Trimer }} \\
(\%)\end{array}$ & 0.2 & 1.2 & 0.0 & 0.0 & 1.1 & 0.5 \\
\hline
\end{tabular}

${ }^{+} \mathrm{mAb}$ solution $(11 \mathrm{mg} / \mathrm{mL})$ with no aggregate spike

${ }^{++}$Aggregate-spiked Ab solution $(11 \mathrm{mg} / \mathrm{mL}) ; \mathrm{mAb}(15 \mathrm{mg} / \mathrm{mL})$ spiked at $1.0 \%$ with $\mathrm{mAb}$ aggregate (11.4\% dimer and $33.3 \%$ trimer or larger species) prepared for application to column chromatography and nylon prefilter and adjusted to $11 \mathrm{mg} / \mathrm{mL}$ for analysis and virus filtration

Table 2 Dimer and trimer or larger species content of aggregate-spiked plasma IgG solutions used in the virus filtration process.

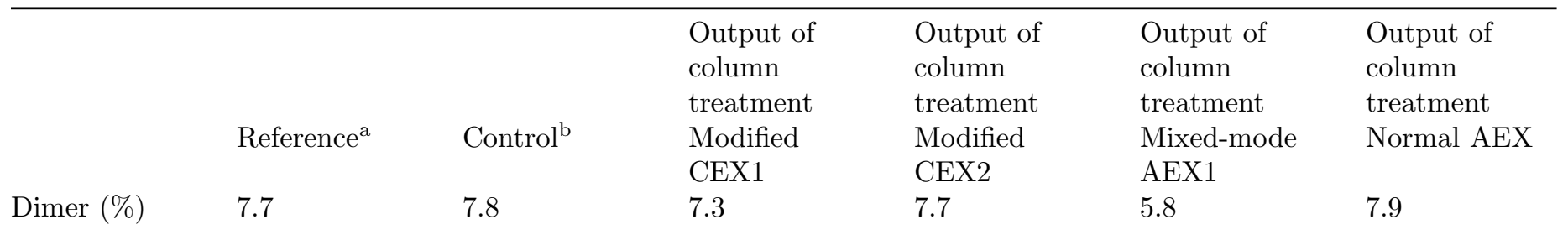




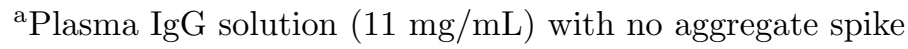

${ }^{\mathrm{b}}$ Aggregate-spiked plasma IgG solution $(11 \mathrm{mg} / \mathrm{mL})$; plasma IgG spiked at $0.5 \%$ with IgG aggregate $(14.8 \%$ dimer and $57.1 \%$ trimer or larger species) prepared for application to column chromatography and adjusted to $11 \mathrm{mg} / \mathrm{mL}$ for analysis and virus filtration

\section{Figure legends}

Figure 1 Filterability of various column chromatography flow-through process outputs of aggregate-spiked $\mathrm{mAb}\left(1.0 \%\right.$ aggregate spike) shown as (a) throughput against filtration time and (b) permeate flux $\left(\mathrm{L} /\left(\mathrm{m}^{2}\right.\right.$ h)) against throughput. For all filtrations, $\mathrm{mAb}$ at $11 \mathrm{mg} / \mathrm{mL}$ in $20 \mathrm{mM}$ Tris-Acetate, $\mathrm{pH} 7$ adjusted to 15 $\mathrm{mS} / \mathrm{cm}$ with $\mathrm{NaCl}$ was filtered at $0.3 \mathrm{MPa}$. Reference (no aggregate spike) and control (aggregate spike) have no column chromatography treatment.

Figure 2 Size exclusion chromatography profiles of mAb solutions. Profiles of $\mathrm{mAb}$ without aggregate spike (reference) and with 1.0\% aggregate spike (control) are shown along with mixed-mode AEX1 flow-through fraction of aggregate-spiked mAb and nylon prefilter filtrate of aggregate-spiked mAb. Peaks of monomer, dimer and trimer and larger ([?]Trimer) aggregates are labeled.

Figure 3 Filterability of various column chromatography flow-through process outputs of aggregate-spiked plasma IgG (0.5\% aggregate spike) shown as (a) throughput against filtration time and (b) permeate flux $\left(\mathrm{L} / \mathrm{m}^{2} \mathrm{~h}\right)$ against throughput. For all filtrations, plasma IgG at $11 \mathrm{mg} / \mathrm{mL}$ in $20 \mathrm{mM}$ sodium acetate, 100 $\mathrm{mM} \mathrm{NaCl}, \mathrm{pH} 6$ was filtered at $0.35 \mathrm{MPa}$. Reference (no aggregate spike) and control (aggregate spike) have no column chromatography treatment.

Figure 4 Comparison of clogging models for aggregate-spiked $\mathrm{mAb}$ (1.0\% aggregate spike) filtrations shown in Figure 1. Experimental values and calculated values for each model are presented for each of these solutions: (a) reference (no aggregate spike), (b) control (1.0\% aggregate spike), (c) mixed-mode AEX1 flowthrough output of aggregate-spiked mAb, (d) normal AEX flow-through output of aggregate-spiked mAb. Clogging models: cake filtration, intermediate, standard and complete. For all filtrations, $\mathrm{mAb}$ at $11 \mathrm{mg} / \mathrm{mL}$ in $20 \mathrm{mM}$ Tris-Acetate, $\mathrm{pH} 7$ adjusted to $15 \mathrm{mS} / \mathrm{cm}$ with $\mathrm{NaCl}$ was filtered at $0.3 \mathrm{MPa}$.

Figure 5 Clogging model analysis for aggregate-spiked $\mathrm{mAb}(1.0 \%$ aggregate spike) filtrations shown in Figure 1 based on (a) clogging factor, $\mathrm{k}$, and (b) mean difference between experimental values and calculated values for each clogging model (calculated using Equation 9). Clogging models: cake filtration, intermediate blocking, standard blocking and complete blocking. $\mathrm{mAb}$ at $11 \mathrm{mg} / \mathrm{mL}$ in $20 \mathrm{mM}$ Tris-Acetate, $\mathrm{pH} 7$ adjusted to $15 \mathrm{mS} / \mathrm{cm}$ with $\mathrm{NaCl}$ was filtered at $0.3 \mathrm{MPa}$. Reference (no aggregate spike) and control (aggregate spike) have no column chromatography treatment.

Figure 6 Comparison of clogging models for aggregate-spiked plasma IgG (0.5\% IgG aggregate spike) filtrations shown in Figure 3. Experimental values and calculated values for each model are presented for each of these solutions: (a) reference (no aggregate spike), (b) control (0.5\% aggregate spike), (c) modified CEX1 flow-through output of aggregate-spiked plasma IgG, (d) normal AEX flow-through output of aggregatespiked plasma IgG. Clogging models: cake filtration, intermediate blocking, standard blocking and complete blocking. For all filtrations, plasma IgG at $11 \mathrm{mg} / \mathrm{mL}$ in $20 \mathrm{mM}$ sodium acetate, $100 \mathrm{mM} \mathrm{NaCl}$, pH 6 was filtered at $0.35 \mathrm{MPa}$.

Figure 7 Clogging model analysis for filtration of aggregate-spiked plasma $\operatorname{IgG}(0.5 \%$ aggregate spike) shown in Figure 3 based on (a) clogging factor, $k$, and (b) mean difference between experimental values and calculated values for each clogging model (calculated using Equation 9). Clogging models: cake filtration, intermediate blocking, standard blocking and complete blocking. Plasma IgG at $11 \mathrm{mg} / \mathrm{mL}$ in $20 \mathrm{mM}$ sodium 
acetate, $100 \mathrm{mM} \mathrm{NaCl}, \mathrm{pH} 6$ was filtered at $0.35 \mathrm{MPa}$. Reference (no aggregate spike) and control (aggregate spike) have no column chromatography treatment.

Figure 8 Extrapolation of experimental filtration values of plasma IgG reference solution (no aggregate spike) shown in Figure 6a based on calculated values for each clogging model. Plasma IgG at $11 \mathrm{mg} / \mathrm{mL}$ in $20 \mathrm{mM}$ sodium acetate, $100 \mathrm{mM} \mathrm{NaCl}, \mathrm{pH} 6$ was filtered at $0.35 \mathrm{MPa}$. Clogging models: cake filtration, intermediate blocking, standard blocking and complete blocking.

\section{Hosted file}

Figure 1.pdf available at https://authorea.com/users/361453/articles/482867-evaluating-andmodeling-the-impacts-of-mixed-mode-and-surface-modified-column-chromatography-on-virusfiltration-performance

\section{Hosted file}

Figure 2.pdf available at https://authorea.com/users/361453/articles/482867-evaluating-andmodeling-the-impacts-of-mixed-mode-and-surface-modified-column-chromatography-on-virusfiltration-performance

\section{Hosted file}

Figure 3.pdf available at https://authorea.com/users/361453/articles/482867-evaluating-andmodeling-the-impacts-of-mixed-mode-and-surface-modified-column-chromatography-on-virusfiltration-performance

\section{Hosted file}

Figure 4.pdf available at https://authorea.com/users/361453/articles/482867-evaluating-andmodeling-the-impacts-of-mixed-mode-and-surface-modified-column-chromatography-on-virusfiltration-performance

\section{Hosted file}

Figure 5.pdf available at https://authorea.com/users/361453/articles/482867-evaluating-andmodeling-the-impacts-of-mixed-mode-and-surface-modified-column-chromatography-on-virusfiltration-performance

\section{Hosted file}

Figure 6.pdf available at https://authorea.com/users/361453/articles/482867-evaluating-andmodeling-the-impacts-of-mixed-mode-and-surface-modified-column-chromatography-on-virusfiltration-performance

\section{Hosted file}

Figure 7.pdf available at https://authorea.com/users/361453/articles/482867-evaluating-andmodeling-the-impacts-of-mixed-mode-and-surface-modified-column-chromatography-on-virusfiltration-performance

\section{Hosted file}

Figure 8.pdf available at https://authorea.com/users/361453/articles/482867-evaluating-andmodeling-the-impacts-of-mixed-mode-and-surface-modified-column-chromatography-on-virusfiltration-performance 